\title{
Strategy of the Low Carbon Economy Based on the Background of Low-carbon Urban Construction
}

\author{
Xudong $\mathrm{Li}^{1, \mathrm{a}}$, Jin $\mathrm{Xie}^{2, \mathrm{~b}}$ \\ ${ }^{1}$ Chongqing University of Science \& Technology, Chongqing, 401331 \\ ${ }^{2}$ Chongqing City Management College, Chongqing, 401331 \\ ${ }^{a}$ email, ${ }^{b}$ email
}

Keywords: Low-carbon Cities, Industrial Structure, New Energy

\begin{abstract}
In today's environment has been severely damaged, protecting the environment and maintaining ecological balance has become the focus of attention of urban construction, in this context, the concept of the rapid spread of low-carbon city. From construction principles, development goals, building programs, institutional mechanism, industrial structure, security and other aspects, some suggestions and measures.
\end{abstract}

\section{Introduction}

The rapid development of modern society, to enhance the people's living standards, while deteriorating ecological environment, such as shortage of resources, a great obstacle air pollution, has become the urban construction. This is a worldwide problem, how to build a low-carbon city, low-carbon economy countries much attention is currently abroad more famous low-carbon cities of New York, London, Malmo, Copenhagen, and so on. As environmental awareness increases, major cities have also embarked on a road of low-carbon, such as Shenzhen, Shanghai, Wuxi, Baoding, Changsha and other places, after years of construction, and achieved good results, but objectively speaking, in Europe and America compared to the national low-carbon standards, there is still a distance. Moreover, in the construction process, there are many problems, such as carbon emissions are still high, still shows a slow growth trend; lack of scientific research and technology and innovation, urban lack of features. Therefore, low-carbon economy in the current context, it should follow the low carbon concept, according to the actual situation around, study the corresponding low-carbon city building strategy.

\section{Clear Construction Principles and Formulate A Reasonable Goal}

Any project needs to have a goal, efforts in the direction indicated, low-carbon urban construction is also true that this is a long-term huge project, every step needs to have reasonable and feasible objectives as a guide, one by one implementation, the final completion of the overall construction. The ultimate goal of low-carbon city is to achieve energy, construction, transportation and other areas of low carbon and green for people to create a good living environment, create more urban civilization. As it involves many areas, the goal is also showing a diverse characteristics, such as in the energy sector, the main goal is to improve energy efficiency, develop new green energy. Transportation is in order to ease the traffic pressure, establish a comprehensive transportation network, promote new technologies and other urban rail. The construction industry is to achieve the goal of saving and green building, improve the quality of life of the people and reduce harm to the environment. Technology is to promote low-carbon technologies and green products, improving people's lifestyle, and enhance the level of consumption of low-carbon cities.

Coordination principles. The so-called low-carbon environment, the key is how to live in harmony with nature, understand nature, the use of natural premise is to respect and protect nature. Modern cities blindly pursue economic development, it is easy to overlook the destruction of nature, very serious consequences. Thus, the relationship between man and nature, between the economy and the environment must be handled properly, take the road of development-saving and 
environmental protection.

Holistic principles. Urban and rural areas are inseparable, while the development of cities, towns should also be followed, so as to form a relatively stable system of urban and rural areas for the city to provide various needs. Some cities only pay attention to the urban areas of towns and villages without concern that a growing gap between urban and rural areas, over time, the city is also very difficult to break. Even in the same city, also often divided into several zones, cities need to be seen as a whole, to strengthen regional cooperation and promote the overall development.

Scientific principles. Low-carbon urban construction, non-overnight matter, need to invest a lot of manpower, material and financial resources, every step is crucial and must correct their attitude, scientific look at the issue, adopt a scientific and feasible solution.

\section{Good Planning Programs to Improve the Existing Mechanisms}

The introduction of the provincial development guidelines, clear low-carbon eco-city development. Set goals for development, low-carbon eco-city development strategies to raise the height of the provincial development strategy, develop long-term development plan. Establishment of the province oriented index system, and the corresponding evaluation index system and monitoring system, the former can evaluate the status of low-carbon eco-city development, which can track and test the process of building a case.

First, improve the incentive system to motivate the work of departments. From government to business, to the general public, should be actively involved. Government to develop incentives to strengthen internal control, supervision departments to do post work, and low-carbon urban construction into the assessment, linked salary system, and fully mobilize the initiative of all sectors. For good business, could be material reward, or give preferential policies. For outstanding performance of the cell and the public, but also it is the appropriate reward model workers selected each year as the benchmark for low-carbon urban construction.

Second, improve the supervision mechanism. Government has continuously improved the constraints and means of supervision, combined with financial and legislative and other means, to achieve a low-carbon eco-city construction supervision and management, and give full play to the supervisory role of the public, businesses and social organizations in low-carbon eco-city construction, give full play to the NPC and the regulatory role of the CPPCC, to encourage the public to express their views through the NPC and CPPCC channels.

\section{To Adjust the Industrial Structure and Focus on Key Areas}

On the one hand, to develop new low-carbon industries, traditional industries and energy consumption are more harmful to the environment, should actively promote new industries, save energy and reduce carbon emissions, protect the environment, such as solar, wind and related products to promote and use.

On the other hand, the traditional industries, can not be completely abandoned but should upgrade to modernize, to adapt to current needs. For high energy consumption, high pollution industry, can gradually be phased out, at the same time promote the upgrading of traditional industries using high technology.

Economy is a measure of the level of urban development of important standards, but history tells us that if the blind economic development, the pursuit of economic efficiency, but will result in serious damage to the ecological environment, so only more costly to control. Modern low-carbon city to promote the development of recycling economy, not only into the circular economy concept in production, but also the gradual penetration in public life. Such as garbage classification and recycling, the city will have a large variety of garbage every day, some after treatment, can change waste into recycling, thus saving energy, which requires garbage classification. Specifically, the chemical industry, water resources, greater use of modern technology can be discharged to wastewater treatment, repeated use; the construction industry will emit large quantities of solid waste, waste can also be recycled, used for paving. Steel and cement industry is a large energy 
consumption, the production process will produce a lot of heat, and pressure, if not to deal seems too wasteful, it may be collected to make electricity, heat use.

People's way of life should also be attendant changes, low-carbon urban construction is that everyone should be some responsibility that requires the active participation of the public, from the side of the little things. Government departments at the same time to promote its low-carbon environmental protection concept, should play a leading role in encouraging people to carbon consumption, such as the purchase of energy-saving lamps, use energy-saving appliances, carry out environmental protection activities. The public to enhance their awareness of energy conservation, as far as possible the use of bicycles, buses and other travel mode, use energy-saving green decoration materials, to contribute their efforts to the construction of low-carbon cities.

Energy is the material basis for the development of the industry running, but also low-carbon urban construction key. Our country is coal country, in the past a very long time, coal is the main source of energy, but a great harm to the environment, and more and more obvious. Countries have strict control of carbon emissions, the introduction of relevant policies, although played a certain role in mitigation, but carbon emissions are still rising. So in the future we should be green carbon concept as a guide to optimize the energy structure, and actively develop new energy sources, especially wind, solar and biomass, which requires collective participation of the whole community, for coal, oil and other energy sources, should improve their utilization, reduce damage to the environment, while promoting non-fossil energy. Adjusting the power structure, promote hydropower, wind power, and strictly control the emissions standards generation of various forms, once beyond the standard, and should be punished accordingly. In order to balance electricity, avoiding energy waste can be taken to phase pricing, to guide the public to conserve electricity.

Traffic occupied building in the city a very important position, with the improvement of living standards, the surge in the number of private cars, although travel more convenient, but also causes environmental pollution, traffic congestion and other focus. In accordance with standard low-carbon city, modern city should establish a green transportation system, the use of clean energy, try to take the bus and subway, or take a bike, walking, etc., to strictly control the travel of private motor vehicles.

Rational planning of urban transportation networks, and establish a low-carbon rail system to ease traffic pressure while reducing environmental pollution damage. In some big cities, should increase the number of bus and subway, optimize transportation routes, be adjusted trip structure of urban residents. Modern many places to promote "20 minutes communities", with its emphasis on making the spatial layout more balanced form of slow traffic system, it is completely separated from the vehicle, whether it is safe or travel speed, than the present situation has improved significantly. Many foreign countries have realized the tram, which is a fast, clean transport, need to be further promoted in our country. To highlight the dominant position of public transport, the city should be established as soon as possible lanes of bus lines for rational planning.

Construction and transportation are important criteria to reflect the level of urban modernization in recent years, the rapid development of China's construction industry, construction technology innovation, increased functionality, and more attention to their environmental benefits. Current construction projects must follow the principle of "green, green, low carbon", and it turns out, the building energy consumption is a great project, so that green building is the way to modern urban construction.

First, the materials and techniques must reflect the green, past the construction will use a lot of chemical materials, the harm is very serious, more and more non-polluting materials are now being developed, to be widely used in green buildings . The development of energy technologies, research-related products, such as LED lighting, energy saving lamps, wall insulation materials, water-saving appliances. Second, the strict implementation of energy efficiency standards for state standards, shall not be contrary, strengthen the supervision of the construction process to ensure that the system fully implemented. At the same time, strengthen quality control, improve construction standards and reduce quality defects, extend the life of the building. Extensive building energy consumption pattern is too large for an intensification of the transition, the housing industry to 
speed up the process.

Energy, transport and construction are the focus of the construction of low-carbon city, but to achieve these, need to modern high-tech-based. In the 21st century, high-tech trend of rapid, ever-changing, plays an irreplaceable role in all areas of construction. So for the modern city, the need to promote a variety of new low-carbon technologies, the formation of a new technology system, such as energy-efficient lighting, building energy conservation, etc., should be the focus of attention. Government departments should develop a high-quality and excellent technical team, he threw himself into the new energy and new technology research and development, including the current wind, solar and other hot technology. Power is an integral part of the city, in order to ensure safe use of electricity, reduce consumption and pollution, should actively develop smart grid. Research departments need to cooperate, currently the most common is the "production integration" model, the government, enterprises, universities joint government enterprise responsible for funding and platform construction, talent training is responsible for the construction of universities and research institutions, as technology raise the level, but also the technology into productivity, research and development related products.

\section{Step Up Publicity Efforts to Do Security Work}

The concept of low-carbon and environmental awareness is particularly important, but also carry out basic guidance and construction of low-carbon, low-carbon city should be encouraged to join the people, so the government should play an exemplary role in guiding the media and public organizations, and industry to strengthen publicity and the low carbon idea spread to the nation, to create a good social environment. In the specific construction, the relevant departments need to pay attention to ecological and environmental problems, to promote its low carbon concept into the focus of the work, and establish environmental protection, energy conservation and new image of the city. Media use the Internet, television, radio and other channels reported that publicity, public organizations by shooting videos, carry out public welfare activities to publicize the education sector should be increased content in teaching.

Low-carbon urban construction involves many aspects, is a long-term project, the need for improved security measures and carry out security work. We set up a special leading group to arrange municipal senior leadership as head of the unified management leadership role. Meanwhile, the joint departments of finance, education, forestry, transportation, science and technology was added to clarify their respective responsibilities, to ensure that every job can be carried out smoothly. Policy, economic and technical support is essential, but also support the construction of the key factors that could be pursued, it should be based on actual requirements for the introduction of relevant policies, expand financing channels to ensure adequate economic input, and gradually establish a good research team.

\section{Conclusion}

Ecological and low-carbon urban construction, modernization goal, the government needs to guide and control the introduction of policies in favor of low-carbon urban construction, and joint public organizations, the media, businesses, citizens to participate, according to the actual situation around, from a technical, energy, systems and other efforts to raise the level of modernization of the city's construction.

\section{Acknowledgements}

Fund Project: Chongqing Municipal Education Commission in 2015 Humanities and social science research projects "based on low-carbon urban construction Countermeasures hierarchy of needs theory" (15KSG187). 


\section{References}

[1] Liu Jun. Strategic Research on the low carbon city development [J]. Technology Progress and Policy, 2016, 33 (1) 45-50.

[2] Li Hui. two Oriented Society Construction of low-carbon city development strategy research - A Case Study of Hunan Area [J]. Urban Development, 2010,17 (9): 47-54

[3] Shi Mengmeng. Low-carbon eco-city development strategy in Shandong Province [D]. Shandong Normal University, 2014.

[4] Zhang Jixian. in Henan is loose low-carbon city strategy and its Realization Approach, [J]. Anyang Teachers College, 2011,24 (2): 79-83.

[5] Liu Zhongwen, Gao Pengzhao, Zhang Ping. Research program of low-carbon urban development strategy model [J]. Science and Technology Progress and Policy, 2010, 27 (22): 67-70.

[6] Xie Gengfang, Yu Kanhua. Promote low-carbon development model and strategy research [J]. urban ecological economy, 2015,31 (6): 84-87. 